\title{
SOCIOLOGICAL STUDY OF NATHPANTHI GOSAYI COMMUNITY IN EAST VIDARBHA
}

\author{
Mr.Dharmadas Ghodeswar
}

\section{INTRODUCTION}

Man is a social animal and different than other animal man has created religion and culture with marriage group, cast and class etc. Man has developed social economical, religion and cultural institution. Today modernization affect on all social institutions directly or indirectly. India is accommodated in developed country but it has plenty of problems such as poverty unemployment, backward classes and cast problems, rural backward social etc. Prof. Rathod classified that Nathpanthi Gosayi community are four types such as class live in middle part of village, outside Dalit, tribal in hilly and forest area and last one who always has roaming stage called as a Bhatka community.

Roaming tribal, nomadic community has extreme poverty and backwardness which are always roaming for searching food. Forest official take their undo advantage for their selfishness. Tribal and nomadic tribal community people are illiterate and simple. They have been easily exploited by such cunning people. The students are in this community are found in extreme backward situation. They don't have aim to peruse study, sincerity for education and fulfillment of parents dream. They prefer their traditional activities them study. The children from Nathpanthi Gosayi community ignore taking education but there are sincere about them study. Very less number of students found who pass 10the std. Therefore Researcher selected this topic for research of overall study of Nathpanthi Gosayi community, in East Vidarbha.

\section{PARAMETERS FOR STUDY OF NATHPANTHIYA GOSAYI}

1) Indian Society - Indian society is very origin and having special feature, detail discussion carried out with context to this research.
Article DOI: https://doi.org/10.36713/epra5571

2) Modernization - As per Karl Marx, modernization is materialism. Modernization has its effects and side effects on society. Modernization is with westernization based on scientific approach. Modernization has vast scope and involve in society, physical change creates confusion in tribal society.

3) Transformation - According to prof. Manik Mane, govt. has extended plenty of developmental work considered as a transformation

4) Accommodation of roaming community -

Roaming community always move place to place for two region viz. fulfillment of economical need and as a part of habit. They formed special their one class. Chandrapur, Nagpur and Bhandara and main districts for such communication

5) Tribal community

6) Structure - Gosayi community has particular type of structure based on primary and simplicity.

\section{IMPORTANCE OF STUDY}

The roaming community population in India is around 10 cores. There are no effect taken at national level for them. Maharashtra Govt. allowed 4\% researcher in Job and education sectors. Today around 100 such communities in main list. Fulfillment of basic need is main aim of their community. As per the perspectives of anthropology the study of such communication is very essential for their development. Frequently they try to come in the list of scheduled cast. Also they prove their cast validity. Many people are there, due to not providing cast validity they lot their Jobs in Nathpanthi Gosawi community. Same problem faced by students. Regional and Natural situation need to understand for the study of human. In this study all social cultural economical and religion aspect we have been included in this study.

Vidarbha is an important part of Maharashtra after organization of $1^{\text {st }}$ May 1960. Total 35 districts and 6 main parts are classified for suitable working of 
administrative process. West Maharashtra, Khandesh, Marathwada are the other parts in Maharashtra.

\section{Geographical Condition of East Vidarbha}

As per the census of 1991, 1.80 cores are in Vidarbha. It included total 11 districts viz. Buldhana, Washim, Akola, Amravati, Yawatmal, Wardha, Nagpur, Chandrapur, Bhandara, Gondia and Gadchiroli Vidarbha has pure cultivate land and produce flora and fauna. All religion and cast gem people, rivers, Industries, temples are well-known in Vidarbha, Nagpur, Chandrapur, Bhandara, Gondia are the district of East Vidarbha. There district have Nathpanthi Gosawi and sub cast viz. Machindranath, Jalandarnath, Goncshnath, Bharatinag, Chaptinath, etc with their special culture and life style. They are buying in different occupations.

The effect of modernization and industrialization noticed on them.

\section{RESEARCH METHODOLOGY}

Research techniques are one of the scientific techniques to gain knowledge. In order to deliver some distribution, research has not brought any significant impact on the population. Amendment is also an integral part of research. It is very difficult to get rid of genetic disciplines in the present life. It is an endless process and the result is based on the conclusion of the society. Enlighten is going on. All kinds of rectification is considered as the basis of the social life of the Pardi Samaj. Prospective research by bringing the nature and process of the society is a quest for innovative thing as a human being a curious and fertile animal with this human effort. Man always tries to clarify and verify existing state truths in the research. To find out the facts or to learn the truth, follow the specific method in this case, this special study is done by scientific way. It is the first step in resolving problems in the classical, social research, system. Each researcher sets a topic for any research work. But the teaching diary choice does not distract from the problem as researchers after selecting the topic of research study. The purpose of research has to be fixed in detail its survey statements. In this way, the purpose of the study is to determine the problems in the particular research.

\section{Importance of topic}

1. To know the social, economical, familiar, educational and health related status of Nanthpandhiy Gosayi Community.

2. For understanding the role of government towards community development.

3. To get information of Nathpanthiya Gosayi holistically in current scenario.

4. Preparation for some plans for enhancement of these communities.
5. Today in the age of globalization, to identify their problems with effective strategy

\section{OBJECTIVES OF RESEARCH}

1. To identify collaboration between roaming and settled Natpanthuya Gosayi community in research area.

2. To get rid from old customs, traditions and superstation to these communities.

3. To get to know basic problems of Nathpanthiya Gosayi community.

4. To understand the negligence of government mechanism towards them.

5. To know about various hidden diseases and other problems of them.

6. To get knowledge about child marriages and not getting second marriage by these women.

7. To understand the disputes causes among the leaders of Nathpanthiya Gosayi community.

8. To provide concrete leadership to them.

9. To get review of developmental plans of government.

10. To get the situation of changes among them

\section{HYPOTHESIS}

1. Econolical status of Gosayi is down

2. Goverment negligence is responsible for their poverty.

3. Due to traditional behavior they are not improved yet economically.

4. Nathpanthiya Gosayi preserve their inheritance.

5. Goverment executed various schemes and plans for them.

Following are important points towards Vidarbha

1) Region

2) Industrial region and natural resources

3) Temperature and rainy season in Vidarbha

4) Natural and cores in Vidarbha

5) Forest and flora in Vidarbha

6) Animals

7) Population

8) Casts in Vidarbha

9) Tribal and scheduled tribunal Vidarbha

10) Nomadic tribes in Vidarbha

11) Rural religion groups in Vidarbha

12) Celebration of festivals

13) Tourism sector in Vidarbha

14) Other supplementary contents

3) Nathpanthi prefers traditional marriages. While investigation one marriage has been taken is a 
registered marriage. Cumulative marriages arranged by politician, social worker etc.

4) Mainly parents take the decision of fixation of marriage; still the gives option is important. Smart, hard worker prefer by community. Also working girl always prefer by them. But Nathpanthi community has very job holding girls so they consider as usual girls involving in farming sector. Inter cast marriage held in Nathpanthya Gosayi communities.

Respondents expressed natural opinion above changing scenario and pattern in these communities. They permitted widow marriages. There is a relaxation than Hindu religion. Dowry system is stigma on every society. Hindu religion, there is a place to dowry on different forms, Nathpanthy Gosayi don't give place to dowry system. 'Doj' is system given by father of girl. $13 \%$ respondents agreed for acceptance of dowry. May be this beginning of dowry in this community. 51\% respondents stronger opposed to dowry system in future. It seems that Gosayi are acceptable for traditional views in modern world.

6) Character and ethics preserved by them. They indirectly allow to unfair relations but strict about sexual activities. They have strict rules about this matter. They give more importance to boy as per the Hindu religion Nathpanthi Gosayi are having modern thoughts and they don't discriminate about Gender inequality.

7) Divorce is a last stage in marriage system. So many side effects of dowry in society, divorce are a negligible in this community. Tantamukti yojana is very useful and they have believed on them.

8) Family is an important of society. Joint and nuclear systems are available in community. Man power provided through joint family. Still in this community, joint forms convert into nucleolus family. 93\% respondent's agreed for in decision making prove considers the view of both. $94.5 \%$ respondent told that socialization schedule carried out by both.

9) Dr. Babasaheb Ambedkar and Swami Vivekanand suggested the importance of education. Therefore government started planning's accordingly.

\section{Recommendation from Kothari commission}

1) Free education till fifth slandered to marginal groups

2) Extension of Ashram School in the region

3) Entry to professional institution

4) Hostel facilities, guidance, scheme to be given to their students.

5) Identity the working youth and provide them basic education. Special jobs given to such youth. Even after so many places there is no expected quality grow the in Nathpanthi Gosayi community. Educational development of this not is not satisfied. Today $31.5 \%$ respondents found illiterate. $33 \%$ taken education till primary level. $4.5 \%$ mean very less reacted till graduate and post graduate. Earlier generation was victim of $91 \%$ literacy. $1.5 \%$ and $7.5 \%$ were having education till primary and middle level.

10) $52 \%$ respondents ready to accept new changes due to social worker, excessive and certain dreams. In some proportion positivity can be noticed in this community, Nathpanthi don't discriminate between boys and girls. $95 \%$ respondents expressed satisfactory view about girl's education mean they are positive about education. $96.5 \%$ respondents are ready to send these kids in other cities for education.

11) Tradition, superstitions, costumes and the important part of this community. Still today educated students agree for this mentality told by some respondents. This is one of the hypotheses in the research.

12) Govt. in some proportion created some opportunities in govt. sectors for their empower ate. This communication recalled in 2006 in special backward class still they face the problem of cast certificate and certain documents expressed by $67.5 \%$ respondent only $1.5 \%$ respondent taken the benefits of such reservation.

13) $88 \%$ respondents assume that they are from Hindu religion. $11 \%$ respondent's failed to express this religion. They suppose Gosayi is a religion. They prefer to nature as God and assume worship according they believe various feature of nature as a Gods act. Magic and certain phenomenon are impressive for them. $77.5 \%$ believes on fate, $5.5 \%$ partially and $14 \%$ don't believe over fate. Positive change noticed among them. Nathpanthi Gosayi believes on cultural aspects and this is one of the one hypothesis in the research, $29.5 \%$ don't back on Bhagat.

14) Alcoholism is very common in Gosayi communities they consume liquor on various festivals. With inspiration Tukdoji Maharaj, 'Gurudeo Seva Mandals' established in their villages so some psychological changes noticed among them about such bad habits Even tobacco cheeping is very common there have 'Totesiem' and family God.

15) Agriculture, farming is new for Gosayi, 55\% respondents involved in agriculture. 35\% are labour and $3 \%$ have jobs. Further $77 \%$ people was in farming sector and only $0.5 \%$ had were in service sector maximum Gosayi involved in labour occupations. Therefore little bit economical change noticed in this community. $15 \%$ respondent has other supplementary occupations. $85 \%$ respondents have only single occupation.

16) Maximum respondents have income between $64.5 \%$ less than 2000. 29.5\% have annual income 
between 20 to 25 thousand only $6 \%$ respondents told that their income is more than 1 lac hence it is noticed that they are economically backward.

17) Even in economical backwards $54.5 \%$ Gosayi are satisfied and $27.5 \%$ are not satisfied over the situation. $18 \%$ Nathpanthi involve in other occupation such as beginning, Kingari and other occupation. Migration is less among them. $43 \%$ respondents told that if they get good response. They can leave the village. Even in more problems is agriculture $82 \%$ respondents want to continue their agriculture occupation.

18) Some physical things noticed in their home $42 \%$ respondents have mud type home. $2.5 \%$ have hut from grass. $25.5 \%$ don't have any type of accommodation. Some people mean construction time sponsored by state government. Gharkul scheme. 27.5\% Gosayi don't have any facility such as electricity and water supply. $87.5 \%$ respondent totally dependent on forest. Wild animals always trouble them. In Taluka only one lady in this community become president of Panchayat Samiti but no special work done by her for others. India today's slogan in shifting India but there is a economic disparity. $33.7 \%$ have far which received in marriage as a gift. Listing radio likes to them. One $0.5 \%$ have TV, Tape recorder and bike etc. summer is very trouble full to them. 57.5\% Nathpanthi don't have toilet facility. They executed from government scheme due to administrative negligence. $35 \%$ respondents have ration card as $7.5 \%$ don't have ration card and Antoday card occasanary they get benefits of such schemes.

19) $3.5 \%$ responders lost their land in govt. projects but they do not received in benefits. $7.5 \%$ used forest land for agriculture. $8 \%$ received land from govt. but it's without any documents.

20) As per act 1976, then is ban on tree cutting 78.5\% Nathpanthi Gosayi bring wood from forest 13.5\% use for other persons. Forest officials trouble and prevent them from such activities.

21) Jawahar Rojgar Yojna and self employment could be improve in to research area but 100 days Rojgar scheme also failed to provide them any type of unemployment. This scheme is not that much effective to eliminates unemployment.

22) Economic back ward and loan have close relationship on the base of $7 / 12$ bank and other financial institutions. This facility is not for landlers Gosayi 50\% Nath Gosavi still maintains their sans facility level and do work in as usual manner. This is one of the positive social changes among them. Gosayi take loan for agriculture market purpose, bank loan is suitable for them told by respondents. Loan sponsored and taken one both process. 5.5\% respondent expressed by their view over dissatisfaction of slavery system.

23) Purchasing capacity and saving one related to each other. Saving is an attitude only $15 \%$ respondents prefers saving, post, Bank and SHG are some of place of savings means this economic condition is so poor. This is one of the hypothecation.

24) Govt. started plenty of schemes for employment of Gosayi. Tribal word use for them and carried out since an ancient time.

25) According to 73 amendment Grampanchayat and Gramsabha have authority $48.5 \%$ respondents expressed their view about such information $76.5 \%$ respondent don't know about any govt. scheme. 12.5\% respondents have taken the benefits from such scheme $86 \%$ respondents executed from govt. developmental plans. $24.5 \%$ respondents directly refused for acceptance of any have from govt. corruption also noticed in these government schemes. $80 \%$ respondents express such schemes are beneficial for them. Gosayi have expectation from government got has to execute various schemes for empowerment. Hence the needs of Gosayi is very less comparative to others.

\section{PROBLEMS}

Initially Gosayi ware accommodate in tribe category. Corruption and simplicity of Gosayi are two main hurdles in front of them. They don't get easily cast and validity certificates. That why they are backward.

Following is the conclusion drawn by researcher after the overall study of Nathpanthy. Gosayi community East Vidarbha. Nathpanthi Gosayi are economically, socially, psychologically and educationally backward. The accommodation are available in some of the district of Vidarbha research carried out and observe required changes in current scenario.

1) Hence Gosayi activity participates in election. This is one of the hypotheses of this research. This a positive change among Gosayi community.

2) 33) Gosayi have glorious history. 95\% Gosayi are unaware about this history and earlier culture. They have influence of Hindu religion. This is also one of the hypotheses of research.

3) 34) Gosayi spent their life fulfillment of basic needs. They don't have facility due to backward and poverty. Frequency Gosayi rehabited for the certain causes. That's why they hamper their original development. This is an interim and will from all sides for the development of whole villager.

4) 35) Today modernization and industrialization shows directly impact on Gosayi. Technical and physical things are impressed to Gosayi. 
5) Social, psychological and awareness noticed among them. Also they raised the attitude of conflict and fight. Still $48.5 \%$ respondents are doing not tell about modernization. 39\% respondents told and agreed for partial and other changes. Many respondents told about their changing life style. Due to modern social, economic and cultural changes occurring in this community. Modernization also create some problem with context to today's age. Still they are still with their old traditions. Bhagat, Magic, fate, believe, rich, extreme mentally of God are in this community. Due to certain completion development is there. Certain things are the symbol of their backwardness. They are the spent victims of all such not required activities.

6) In developmental process, Gosayi are backward and this is also hypothesis for this research.

\section{CONCLUSION}

There is need to push research about Gosayi and special encouragement to be given for research. Development design to be formed with consultant to research for saving time and effects. Reservation an caste, play important role and provided facilities for them. Through survey, cast and cast validity certificate to be provided to them in their home.Resection is based on the cast so researcher should be there accordingly.Economical base should be for reservation and plans. Cast based facilities should be ignoring. Researcher want to this situation would be prolonged in the research area.Economical and psychological mark of facilities. Cast is not the part of such facilities Grampanchayat has special rights for cast related issues.Developmental plans, schemes, facility are essential for social empowerment.Educational facilities are on the based on their regional situation. Gramin and tribal syllabus should frame on the base of their understanding. In that way students can take interest.There is a special creation of museum for preservance of folk language, literature and certain contents. Cultural heritage need to protect for further generation.Relaxation should be given for English and Math. Students will lost their fewer and will learn education. They should be extensive plan in researcher for overall development and empowerment of Nathpanthy Gosayi of East Vidarbha. In constitution $7.5 \%$ for SC and $14 \%$ researcher. Gosayi are not aware about recreation 99\% respondents are aware about researcher. Hence it is prove that Nathpanthi Gosayi are not aware about anything new changes in administrate systems, Education still long forms
them.Gosayi have rights on natural things. Still they have many forest acts restrictions. $75 \%$ respondents agreed that they are executed from their rights. This a charge observed by researcher among the Gosayi. Hence earlier, Gosayi were not aware about these rights but now they think about such matter. This is also one of the hypotheses for into conflict. They proved to enter their name for exclusion in the 50 list category. Today their names included in the schedule cast list but cast validity problem is there so they are not getting year benefits.

According to UNO, Tribes are excluded group from common society. Nathpanthi Gosayi is also a very hard worker. $75 \%$. Gosayi respondent's agreed the exploitation from rich farmer contractor, and government schemes. They failed in economic prosperity and education only 5\% Gosayi registered their complains. It is true that all benefits of scheduled casts getting to them. So they social and economic life enhance but they are long from research from various causes other people get benefits but Gosayi are none interested with context to this process.

$83 \%$ respondent's solely agreed that they are backward in education. $21.5 \%$ respondent noticed secondary treatment given by others. $55.5 \%$ respondent's do not notice such behavior in society. $\mathrm{OBC}$ is mainly cast which see secondary to them. That is speed of social change is slow among them.

Nathpanthi Gosayi have their special folk language like other tribes culture and lifestyle. They knew Marathi and Hindi in less quality. Toady Govt. trying the best to provide education in English language also. They are traditional in their costume. They also try to follow to wear dress like other people. Only $0.5 \%$ Gosayi follow cast related taboo but other don't follow restrictions. Gosayi involve in the social and cultural activities of other community also Gosayi reflect the impact of modernization on their lifestyle, entertainment and other aspects they are changes thoroughly. This is the symbol of social change. Gosayi development and change is less than other due to various regions. Therefore Gosayi backward in social transformation. This is one of the hypothesis in the research.

Gosayi have formal and informal organization of community especially on the base of cast. Leaders are always in organization. Gosayi have some leaders and organizations. They also actively participate in election process. As usual after election, leader ignore to them. This happens in every every election. $27 \%$ respondents do not tell any problem. Grampanchyat is mainly preferable for them. Maximum disputes dissolve in Tantamukti committee. Basically Nathpanthi are so far and peaceful by attitude. Still they are aware about their right as feel by researcher.Gosayi 
are aware about election. Gosayi cast $100 \%$ votes than other educated community. To cast vote is an important for them. The leader in their command suggest them for whom to cast the vote $53.5 \%$ respondents prefer a good and moral full candidate. $26.5 \%$ are close to political party and $73.5 \%$ are free any political portion. Still they have an impact of cast over election.

Tribes were rolling over Gond of Vidarbha. They were ruler between $9^{\text {th }}$ to $12^{\text {th }}$ centuries. Therefore they are impressed over election program. In the research, $16 \%$ Gosayi cast their votes once $0.4 \%$ twice and $2 \%$ stand thrice in the election. The proportion is high with ration of population. But their field is limited any Grampanchayat and Panchyat Samitee. 19\% respondents was election till.

\section{REFERENCES}

1. Banks, J.A., 1972, The Sociology of Social Movements, London, Macmillan.

2. Desai, A.R., (ed.) 1979, Peasant Struggles in India, Bombay, Oxford University Press.

3. Dhanagare D.N., 1983, Peasant Movements in India 1920-1950, Delhi, OUP.

4. Gore M.S., 1993, The Social Context of an Ideology: Ambedkar"s Political and Social Thoughts, New Delhi, sage.

5. Oommen T.K., 1990, Protest and Change: Studies in Social movements, Delhi, Sage.

6. Rao M.S.A., 1979, Social Movements in India, New Delhi, Manohar.

7. Singh K.S., 1982, Tribal Movements in India, New Delhi, Manohar.

8. Selliot Eleanor, 1995, From Untouchable to Dalit: Essays on the Ambedkar Movement, New delhi, Manohar. 